\title{
An Integrated Decision Support System to Define the Best Scenario for the Adaptive Sustainable Re-Use of Cultural Heritage in Southern Italy
}

\author{
Lucia Della Spina ${ }^{(\bowtie)}(\mathbb{D}$, Claudia Giorno, \\ and Ruggiero Galati Casmiro \\ Mediterranea University, Reggio Calabria, Italy \\ lucia.dellaspina@unirc.it
}

\begin{abstract}
The objective of this document is to propose an integrated evaluation model to support the choice of an alternative of an historic industrial archeology building located in Southern Italy, in order to define a strategy shared based on a "bottom-up approach". The methodological path, in consideration of the needs of the local community and of the historic and cultural values of the historic building, is able to verify the feasibility and economic sustainability of the hypothesis in relation to different management models that involve different forms of public-private partnership. The positive results obtained show that the proposed model can be a useful decision support tool in contexts characterized by high complexity, where the goal is to build shared development strategies.
\end{abstract}

Keywords: Strategic evaluation - Circular economy - Sustainable re-use of cultural heritage $\cdot$ Multi-Criteria decision aid $\cdot$ Economic evaluation $\cdot$ Financial sustainability

\section{Introduction}

In the last few decades, researches and debates at an international level have seen the attribution of an increasingly significant role to cultural heritage within the framework of development models based on local peculiarities and on the enhancement of the endogenous resources of the territories. In particular, cultural identities have taken on new values and specificities also thanks to the implications of an intangible nature such as those related to traditions, knowledge and creativity - that have enriched the notion of heritage. It has been recognized that the process of preservation and enhancement of cultural heritage - addressed to all the other resources which characterized and represented the distinctive signs that history has sedimented in a territory if supported by "system" strategies can play an important function both in preserving the resources that promote and support the economic development of local communities. The involvement of local communities, also implemented through the networking of the main stakeholders in the area, raises awareness of cultural heritage, understood as the ability of citizens to recognize their identity in that heritage, to recognize it as their own and, consequently, to cooperate for its conservation. 
To guarantee the collective interest in the processes of enhancing the cultural heritage, it is necessary to define sustainable strategies that must take conservation as a priority and, at the same time, be able to trigger virtuous circles of territorial and local development. These purposes can only be achieved by a public administration capable of governing the entire decision-making process that leads to a programming of the sustainable management of these assets, by equipping itself with tools to support decisions (Fusco Girard and Nijkamp 1997; Della Spina 2019a, b; Della Spina 2020; Nesticò et al. 2018).

As part of the broader theme of cultural heritage and building and urban recovery in particular, the reuse of public buildings with cultural value offers significant opportunities to start sustainable development processes. In this case, it is essential to verify the impacts that the new activities/functions established can produce and the positive effects in terms of widespread recovery processes.

In accordance with the principle of sustainable protection of public real estate, the preventive evaluation of re-use choices has the aim of ensuring the safeguarding of cultural values in the actions to enhance existing building resources. In particular, the new functions must be able not only to protect the identity of the asset, guarantee significant growth in economic and social values, but also be feasible and sustainable in the long term from an economic point of view (Fusco Girard and Nijkamp 1997; Calabrò and Della Spina 2019; Dolores et al. 2020). In this regard, the expectations of the community are decisive in the definition of the re-use strategies and can contribute to the improvement of the quality of life, increasing functional endowments, infrastructures and services, with positive implications on the socio-economic context. On the contrary, public policies and reuse choices are often implemented in the absence of large-scale strategies, capable of achieving integration between the physical, economic and social values expressed by the artifacts to be recovered and the contexts in which they are inserted.

In this document, a multi-group and multi-criteria decision support method (Ishizaka and Nemery 2013) has been applied to support the decision-making process related to the strategies of re-use of disused and abandoned cultural heritage, in a perspective of circular economy (Fusco Girard and Gravagnuolo 2017; Della Spina et al. 2019).

The methodological path incorporates the needs of the local community but does not neglect the historic and cultural values of the heritage, as well as the economic and financial ones.

The methodology follows the general approach to decision (Simon 1972), adapted to the case study analyzed to support the public administration - the owner of the area to choose the best alternative re-use functions from a sustainable perspective and to build shared development strategies (Della Spina and Calabrò 2018; Nestico and Maselli 2020).

In this context, the document proposes an integrated evaluation model, which combines multi-criteria methodologies and economic-financial analysis, in order to classify the alternatives and define the most suitable scenario according to the expectations of the interested parties (Della Spina 2019; Pinto et al. 2017).

Finally, in order to evaluate the hypothesis of alternative reuse of the public asset under study, was verified the level of profitability and economic sustainability in the 
management phase, in relation to the choice of a management model in public-private partnership.

The paper is organized as follows. In Sect. 2, the case study is illustrated. Section 3 describes the methodology adopted. In Sect. 4, discussion of results and future research is presented.

\section{Case Study}

The case study in question concerns the reuse of the Gasometer, a plant that represents a rare Italian example of industrial archeology, of historic value, whose original structure dates back to 1878. The industrial building is located in the historic center of the municipality of Catanzaro, a city located in the south of Italy. The city which is the regional capital is an important administrative, commercial and cultural center, with considerable administrative functions at a regional level. The development strategy of the municipal administration is mainly oriented towards the redevelopment and regeneration of degraded urban spaces in the historic city center.

The Gasometer is located inside the "Valletta Park" a "central" area, it represents a possibility of valorisation and requalification of an abandoned and disqualified marginal area adjacent to the surface metro station of Catanzaro Sala. Today only the iron frame of the old Gasometer, the factory, the warehouses and the building remain of the original structure. The architectural style is the classic one of the French, English and Belgian industries. The exposed masonry is obtained with living stone from the Catanzaro area, the local building material, and constitutes its most valuable element.

\section{Methodology}

\subsection{The Integrated Decision Support System}

The methodological approach used for the case study is based on deliberative evaluation methods and Multi-Stakeholder Decision Analysis (M-SDA) capable of creating an interaction between the different actors involved towards a shared vision, taking into account the strategic role that cultural heritage can play in a circular economy perspective (Fusco Girard and Gravagnuolo 2017; Della Spina 2019; Geissdoerfer 2017).

The proposed methodology aims to include multiple dimensions in the evaluation process to support the identification of re-use and sustainable development strategies, including knowledge of experts and the community. The choice of a participatory methodology is aimed at supporting the co-learning and co-planning process towards a proposal for a new shared action plan for the historic center of Catanzaro.

The result is a hybrid methodological approach for the design of complex urban regeneration processes, capable of assessing which new uses/functions and scenarios could be more suitable for implementing a circular development model (Kirchherr et al. 2017; Mao et al. 2018; Potting et al. 2017). The approach combines, in the various stages of the decision-making process, multi-criteria methodologies and a feasibility/sustainability analysis of the intervention, in order to develop a tool to 
improve the quality and reliability of the internal decision-making process which also concerns the management phase of the historic asset.

Based on a survey of the existing literature, the methodology follows a workflow (Fig. 1) in which the first step concerned the involvement of the interested parties, in which participation techniques were used, capable of creating an interactive relationship between "expert knowledge" and "common knowledge" (Yang 2014; Bourne 2005; Dente et al. 2014). This was useful to understand the role played by the parties involved and their power to influence decision makers in identifying potential actions capable of triggering the multidimensional productivity processes of the city.

In this first phase of the decision-making process, the Decision Maker (DM) identifies the problems, opportunities and objectives related to the project of reuse of the cultural heritage in disuse and to be redeveloped. To achieve this, a list of criteria has been identified. The list of criteria was structured on the basis of when it emerged also in a focus group with the public administration and technicians (Dyson et al. 2015).

The next step is to define five alternatives/scenarios, defined during a focus group organized by the public administration with experts (architect, economist and sociologists) and political representatives. The idea is to evaluate which are the best performing scenarios/alternatives for most stakeholders (Della Spina 2019).

A multi-criteria and multi-group evaluation was developed through the application of the Novel Approach to Imprecise Assessment and Decision Environments (NAIADE) and Analytic Network Process (ANP) (Saaty 1996; 2005; 2006) to evaluate the alternative urban regeneration scenarios that are emerged as significant, incorporating internal and external dependencies between the sets of criteria identified (Munda 2004; Gamboa and Munda 2007) and the interrelationships between the various dimensions: economic, social, environmental and cultural, into the evaluation process. The choice of criteria (cluster) derives directly from the alternatives (Munda 2004) and represents the technical translation of the objectives and needs of the actors, resulting from the institutional analysis and elaborated by the research group.

The final result of the multi-criterion assessment is the identification of the perceived preferable scenario and a preference ranking among the alternatives/scenarios of the participatory process.

The objective of the chosen reuse project is to restore the former Gasometer's use value to make it a "creativity hub", an integrated place of production, consumption and cultural innovation, in which to experience the promotion of culture, the aggregation of young people and creativity as useful elements to amplify and improve the effects of innovation organizational (Della Spina et al. 2016). The reuse project, closely linked to the various interventions envisaged within the municipal structural plan, aims to optimize artistic production, improve the usability of cultural heritage and aims to create an integrated and innovative management system between cultural actors, as an element able to multiply, qualify and diversify the cultural offer and improve its use (Della Spina et al. 2019; Della Spina 2019; Della Spina 2020).

Finally, on the scenario perceived as preferable, the profitability and sustainability of the re-use project in the management phase is verified.

In this document, the application to the case study will focus in particular on this last phase, postponing the study of the methodology used for selecting the best 
performing scenario to studies and publications edited by the authors themselves (Della Spina et al. 2019; Della Spina 2019; Della Spina 2020; Della Spina et al. 2016; Della Spina and Calabrò 2018; Calabrò and Della Spina 2015).

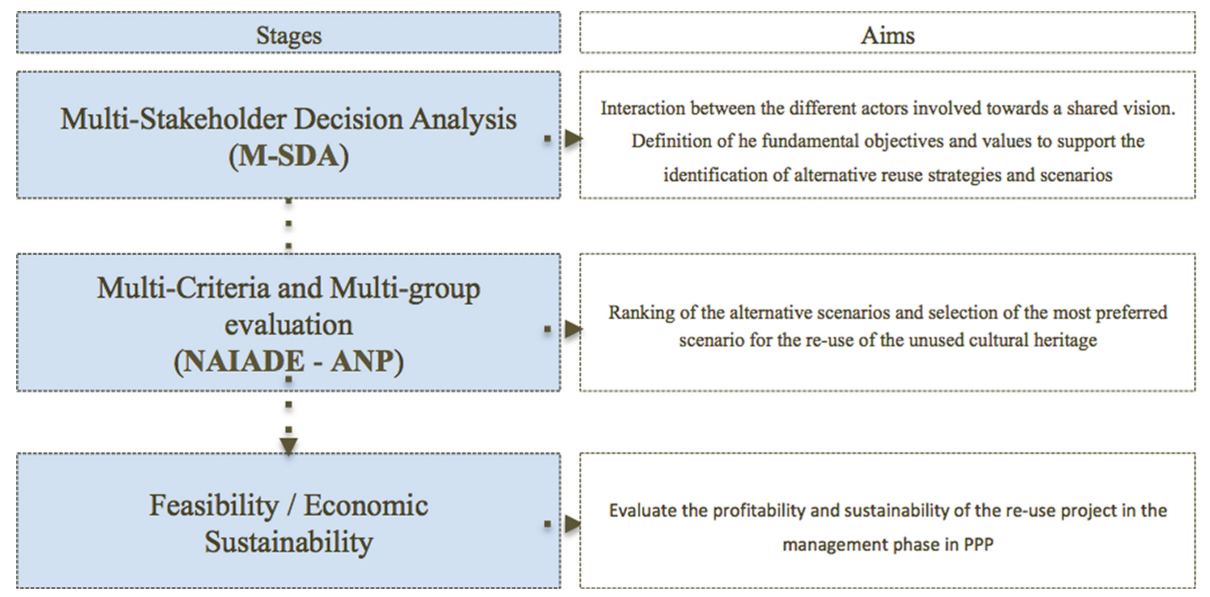

Fig. 1. Multi-methodological evaluation process

\subsection{Choice of the Management Model: Feasibility/Economic Sustainability}

Today, more than in the past, the scarce availability of public money pushes technicians and public administrators to evaluate possible investments in a preventive way (Roscelli 2014; Forte and De Rossi 1992; Prizzon 1995; Realfonzo 1994).

Unfortunately, is frequent the construction of works not strictly necessary, which offer services on an occasional and non-continuous basis and which weigh on public budgets in terms of management costs (Calabrò and Della Spina 2018; Calabrò 2019).

Evaluating investments at this moment means verifying on the one hand verifying the convenience for the community and on the other also the convenience of private subjects, with a view to identifying for which works and to what extent the involvement of private capital in the realization can be foreseen and management of the intervention (Della Spina and Calabrò 2018; Calabrò et al. 2018).

The theme of the Public-Private Partnership (PPP) therefore becomes closely connected to economic-social and economic-financial convenience, because only in conditions of "balance" can a collaboration be established between two subjects that have different purposes (social utility and financial profit).

In assessing the opportunity of a given public investment, one of the fundamental moments is represented by the analysis of alternatives, with the consequent choice of the best solution.

In the case study in question, on the best re-use scenario, selected through the multi-methodological evaluation process, briefly described in the previous section (Della Spina et al. 2019), was verified the feasibility and economic sustainability 
(Dolores et al. 2020) of the intervention in the management phase to regime, in order to verify the management balance and the ability to ensure economic sustainability over a period of time equal to the life cycle of the project (Calabrò 2019; Calabrò and Della Spina, 2018; Calabrò et al. 2018).

The choice of the management model is the preliminary phase to the definition of the total investment costs and management revenues generated by the project (Roscelli 2014; Forte and De Rossi 1992; Prizzon 1995; Realfonzo 1994; Della Spina and Calabrò 2015; Calabrò and Della Spina 2018).

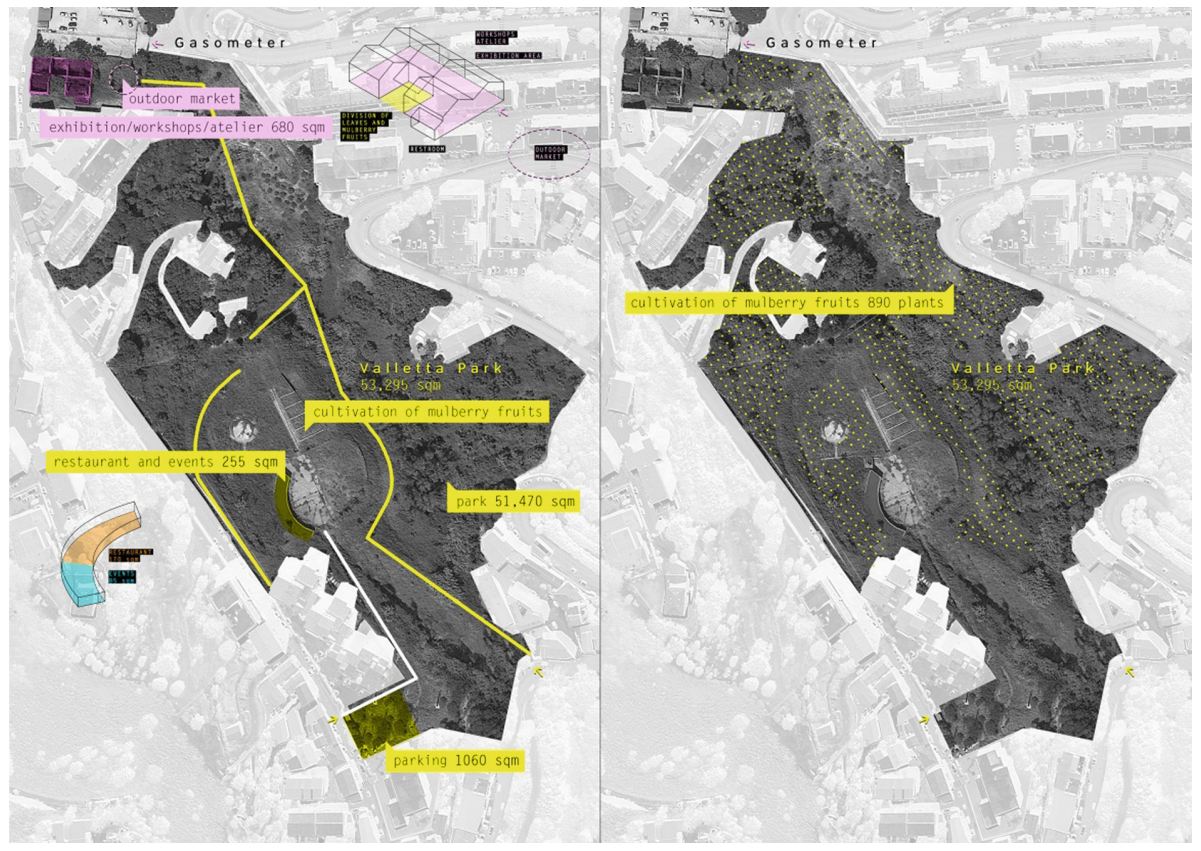

Fig. 2. Re-use project

Once the reuse project has been defined (see Fig. 2), it is possible to evaluate:

- Investment costs (Investments for the recovery and reuse of buildings, Investments for the usability of real estate, Investments for communication and marketing) (see Appendix A).

- Management costs (Identification of the management model and of the manager; evaluation of the human resources plan, evaluation of the management costs, consumables, services, human resources, etc.) (see Appendix B).

- Estimated Revenue (Identification of the products to be produced or services to be supplied; Estimate of their unit sales price; Identification of the reference target; Estimate of the demand to be satisfied based on the reference objective; Evaluation of revenues) (see Appendix C). 
- Feasibility and economic sustainability of the project in the management phase to regime. (see Appendix D).

The costs and revenues for each function were assessed through a market analysis and by referring to the official list prices. The evaluation used a direct approach, through comparison with historical data, when available, and an indirect approach, when it was not possible to find historical data (Roscelli 2014; Forte and De Rossi 1992; Prizzon 1995; Realfonzo 1994; Della Spina and Calabrò 2015).

\section{G a someter}

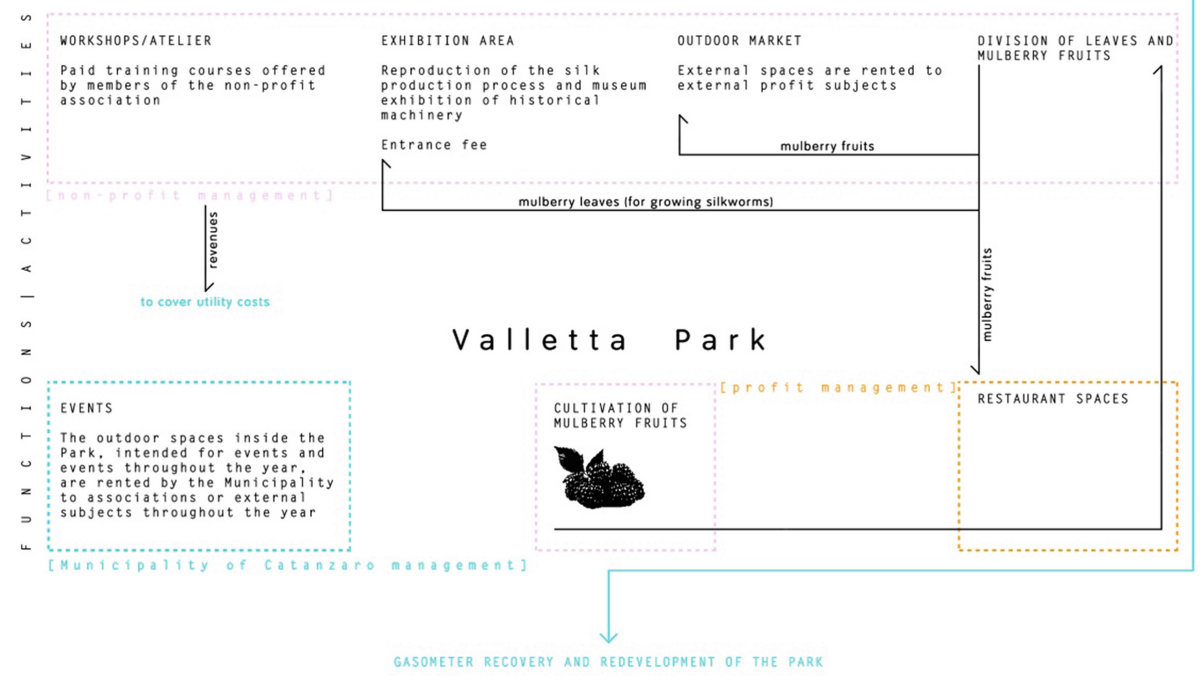

Fig. 3. The management model

In the hypothesized management model (Fig. 3), the Municipality of Catanzaro will bear the costs of the investment for the recovery of the Ex Gasometer and for the redevelopment of the related area of the Valletta Park (Appendix A).

The estimate of operating revenues is a crucial point of the analysis, whether it is a public work or whether it is carried out and/or managed by private entities (Appendix C).

Operationally, it is necessary to calculate the catchment area and make a balance between potential demand and existing supply, to check if there is an unfulfilled demand share that "reasons" in some way the realization of the work. The difference between potential demand and satisfied demand determines the possible residual demand, which can highlight a space in the market or, on the contrary, an already saturated situation. This is obviously a simplification, since if the service offered is better you can think that it will subtract from the competition. Conversely, even in the presence of a residual demand share, in the face of a service of lower quality than what already exists, it may not be able to capture a sufficient number of users for optimal operation (Roscelli 2014; Calabrò and Della Spina 2018). 
The new uses/functions envisaged for the Gasometer area have as reference the target the population of the municipality of Catanzaro. It was considered a territorial water catchment area within a radius of $10 \mathrm{~km}$ and the potential flows of travelers of the Catanzaro Sala railway station, which will be reactivated in the short term (Fig. 4).

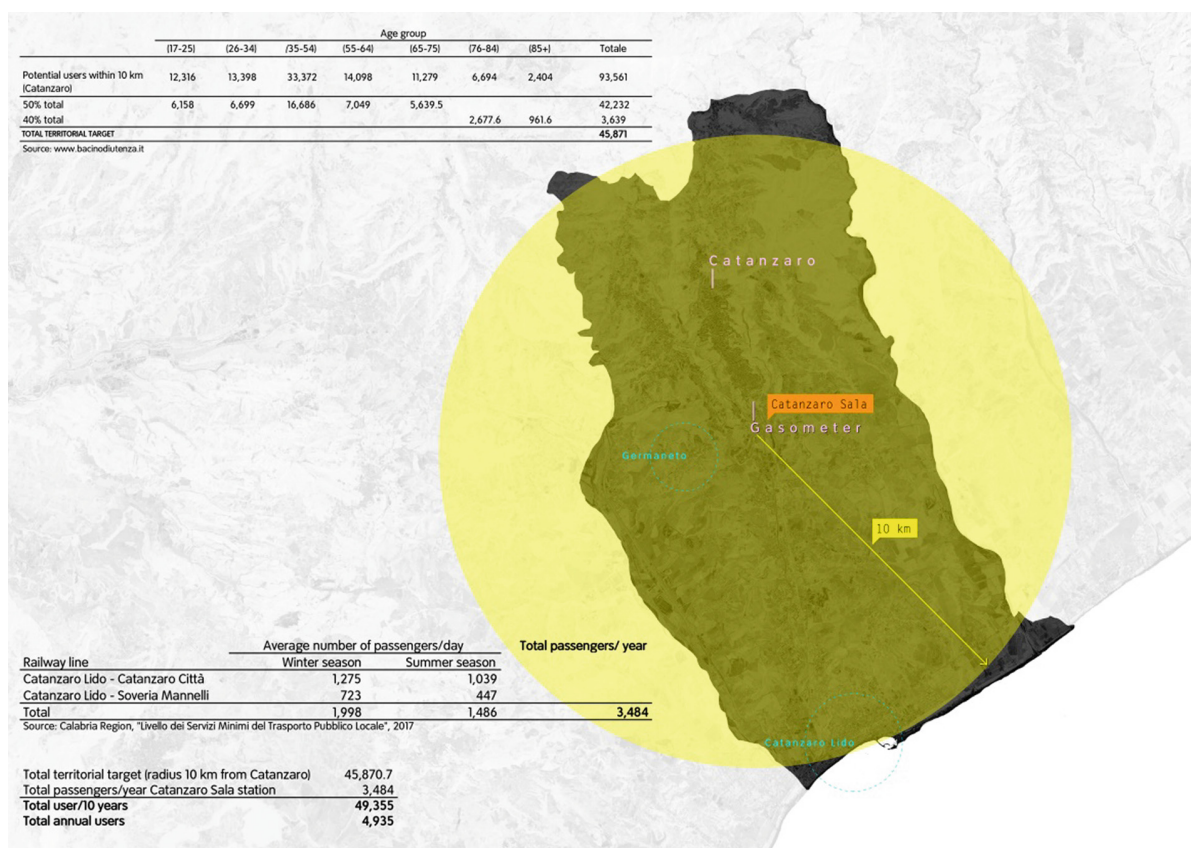

Fig. 4. Analysis of the user base

In the hypothesized management model, the Municipality will entrust the management of the activities envisaged within the Gasometer and of the care of the park's greenery to non-profit associations.

In addition, the outdoor spaces will be rented for events and shows throughout the year. The revenues from the activities to be placed within the Gasometer (laboratories/ ateliers/market) will cover the costs for utilities and human resources for the staff involved in the care of the mulberry trees and park greenery (Appendix B and C).

The semi-circular building located in the lower part of the park will instead be leased by the Municipality of Catanzaro to a private external profit subject (Figs. 2, 3 and 5). 


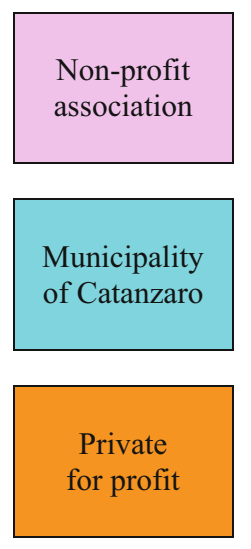

\section{Gasometer \\ Revenues \\ Management costs}

\section{Valletta Park}

Incomes

Management costs

\subsection{Restaurant spaces}

Revenues

Management costs
$105,800.00 €$

$\frac{105,213.58 €}{\mathbf{5 8 6 . 4 3} €}$

Net balance

$39,000.00 €$

Net balance $\quad \mathbf{3 9 , 0 0 0 . 0 0 €}$

$196,560.00 €$

$\frac{151,490.00 €}{\mathbf{4 5 , 0 7 0 . 0 0 €}}$

Fig. 5. Sustainability of the intervention in the management phase to regime

The area of the Gasometer and the Valletta Park, thanks to an initial public investment, would be entrusted to two different managing bodies (Fig. 5), the spaces of the Gasometer and the care of the park to a non-profit association, while part of the semi building -circulate to the bottom of the valley to a profit external subject Appendix B).

In the management hypothesis taken into consideration, the non-profit association, thanks to the revenues from the proposed training courses, the exhibitions set up inside the Gasometer, the sale of mulberries and the rent of the area in front of the area market, would be able to fully cover the management costs borne by it and to have a profit that could be used by the same association to organize events or contact external people to hold lessons inside the fashion workshops (Appendix C).

The private profit, by renting the spaces of the Municipality within the park, would be able to support its restaurant business (Appendix C).

\section{Discussion and Future Research}

This document presents an integrated methodological approach for the choice of sustainable alternative functions for adaptive re-use in a circular economic perspective of the ex Gasometer, a historic industrial archeology building located in Southern Italy (Della Spina et al. 2019; Della Spina and Calabrò 2018).

The proposed methodology integrates different evaluation methods to support the whole decision-making process, characterized by numerous elements of complexity, from the problem definition phase to the assessment of the feasibility and economicfinancial sustainability of the chosen re-use scenario, taking into account the opinions of the different experts involved in the problem (Simon 1972).

The evaluation process to support the identification of re-use and sustainable development strategies for disused cultural heritage aims to include multiple dimensions, including expert and community knowledge, in order to define a "solution of greater compromise", feasible as well as sustainable in the long term from an economic point of view. 
The results obtained show that the re-use scenario, chosen through a multi-group and multi-criteria decision-making process, and the chosen PPP management model is feasible and economically sustainable.

Many experiments show that the public administration, which is characterized by the availability of an invaluable cultural heritage, does not have the sufficient economic and managerial capacity necessary to keep this heritage efficient over time and, therefore, sees the private interlocutor (profit or non profit) the key actor with whom to collaborate and cooperate for enhancement projects, aimed at promoting and supporting entrepreneurship and employment, in particular youth, by supporting innovative forms of business capable to raise the quality of the cultural offer, both local and national. (Calabrò and Della Spina 2018; Calabrò et al. 2018; Della Spina and Calabrò 2018; Calabrò and Della Spina 2019).

The results obtained from the decision support process show that the re-use scenario, identified through a multi-group and multi-criteria decision process, and in particular the chosen PPP management model, is feasible as well as sustainable in the long term by a from an economic point of view, as operating revenues allow full coverage of operating costs, including ordinary and extraordinary maintenance, without additional charges and costs for the public sector (Della Spina and Calabrò 2015; Della Spina and Calabrò 2018; Calabrò and Della Spina 2019).

The overall consistency of the results obtained also highlights that the involvement of non-profit associations in the management model of the public good is relevant not only for the economic sustainability of the project, but also for the emancipation of the local communities and the re-appropriation of their identity, indispensable for triggering virtuous processes of local development (Della Spina 2020).

Today, the new challenge for local authorities is to regenerate abandoned and disused heritage buildings, in a process that must necessarily involve the various stakeholders and the local community in order to create new governance models that are capable of to guarantee economic sustainability and the conservation of historic heritage and cultural values, as in the case of the former Gasometer, which has always been a symbol for the local community (Della Spina et al. 2019).

From this perspective, the study could have interesting political implications in the challenge faced by decision-makers in rethinking the planning and design of a general plan aimed at relaunching and enhancing the immense historic heritage with a view to circular economy, economic development of the territory, which identifies the keys to a culture-led regeneration process in adaptive reuse and cultural and creative (Della Spina et al. 2019; Della Spina 2020; Vickery 2007).

Author Contributions. The contribution is the result of the joint effort of the authors. Despite the global responsibility for the work being equally shared between the three authors, Lucia Della Spina is responsible for Sects. 3 and 4, while Claudia Giorno e Ruggiero Galati Casmiro are responsible for Sects. 2 and Appendix. The abstract and introduction are the result of the joint work of the three authors. 


\section{Appendix A - ESTIMATED INVESTMENT COSTS}

\begin{tabular}{l|l|l|l}
\hline PART I - INVESTMENT FOR THE RECOVERY AND RE-USE OF REAL ESTATE \\
\hline & $\begin{array}{l}\text { Unit } \\
(\mathrm{sqm})\end{array}$ & $\begin{array}{l}\text { Construction } \\
\text { Cost (euro/sqm) }\end{array}$ & Total (euro) \\
\hline
\end{tabular}

A - Estimated construction cost

\section{A.1. Gasometer}

Property recovery

965

680.00

$656.200,00$

A.2. Valletta Park

External arrangement and planting of mulberries

Parking

Driveway

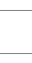

Amount of completion and redevelopment of

"Valletta Park" project (2002-2010)

Photovoltaic system

A - Total costs for auction based works

\begin{tabular}{l|c|c|l} 
& 51,470 & 6.00 & $308,820.00$ \\
& 1,060 & 38.00 & $40,280.00$ \\
\hline & 610 & 53.00 & $32,330.00$ \\
\hline & & & $2,424,240.00$ \\
\hline & 255 & $2,000.00$ & $5,000.00$ \\
\hline \multicolumn{2}{|l}{ of } & $3,466,870.00$ \\
\hline
\end{tabular}

of which:
reduction)

\section{B - Estimate of the sums available to the promoter}

B.1 Economic jobs planned and excluded from the contract

B.2. Topographical survey, findings and geological surveys

0.00

B.3 Allacciamenti ai pubblici servizi (VAT included))

0.00

B.4 Unexpected costs

B.5 Acquisition of areas or assets

0.00

$104,006.10$

B.6 Provision for the adjustment of the prices (referred to art. 133, c. 3 del D. Lgs. 163/2006)

B.7 Incentive expenses (referred to art. 92, c. 5 del D.Lgs. 163/2006)

0.00

0.00

$34,668.70$

B.8 Technical expenses (planning, works management, daily assistance and works accounting)

B.9 Technical expenses (planning, works management, daily assistance and $208,012.20$ works accounting)

B.10 Expenses for consultancy and support activities

$34,668.70$

B.11 Possible expenses for selection boards

0.00

0.00

B.12 Expenses for advertising and, where applicable, for artistic works

0.00

B.13 Expenses for laboratory tests, technical checks and work tests

B.a - Total sums available to the Promoter excluding VAT

$416,024.40$

B 14. VAT (if not recoverable) and any other taxes

B.b - Total sums available to the Promoter including VAT

\section{SUMMARY I - INVESTMENT FOR THE RECOVERY AND RE-USE OF BUILDINGS (PRODUCTION COST)}
A) Total costs auction based works
B) Sums available to the Promoter
I - Total investment for the recovery and re-use of real estate 
PART II - INVESTMENT FOR REAL ESTATE USABILITY

\begin{tabular}{|c|c|c|c|}
\hline $\begin{array}{l}\text { Equipment for silkworm display area (cost per } \\
\text { body) }\end{array}$ & 1 & - & $200,000.00$ \\
\hline Tables & 20 & 120.00 & $2,400.00$ \\
\hline Chairs & 300 & 30.00 & $9,000.00$ \\
\hline Cutlery and crockery & 70 & 15.00 & $1,050.00$ \\
\hline Linen & 17 & 30.00 & 510.00 \\
\hline Workbench & 1 & $4,800.00$ & $4,800.00$ \\
\hline Cut counter & 1 & $5,000.00$ & $5,000.00$ \\
\hline Hob & 1 & $1,200.00$ & $1,200.00$ \\
\hline Washbasin & 1 & $1,300.00$ & $1,300.00$ \\
\hline Oven & 1 & $5,700.00$ & $5,700.00$ \\
\hline Fridge & 1 & 700.00 & 700.00 \\
\hline Dishwasher & 1 & 640.00 & 640.00 \\
\hline Pots & 1 & 580.00 & 580.00 \\
\hline Fryer & 1 & 640.00 & 640.00 \\
\hline Kitchen Robot & 1 & 410.00 & 410.00 \\
\hline Lighting System & & $3,000.00$ & $3,000.00$ \\
\hline \multicolumn{3}{|c|}{ C.1 - Costs Furniture excluding VAT } & $236,930.00$ \\
\hline \multicolumn{4}{|c|}{ C.2 - Estimated cost of hardware and software equipment } \\
\hline Computer & 1 & 480.00 & 480.00 \\
\hline Printer & 1 & 320.00 & 320.00 \\
\hline Sound system & 8 & 200.00 & $1,600.00$ \\
\hline Cash register & 1 & 760.00 & 760.00 \\
\hline \multicolumn{3}{|c|}{ C. 2 - Costs equipment excluding VAT } & $3,160.00$ \\
\hline \multicolumn{4}{|c|}{ SUMMARY II - INVESTMENT FOR REAL ESTATE USABILITY } \\
\hline \multicolumn{3}{|c|}{ C. 1 - Costs furniture } & $236,930.00$ \\
\hline \multicolumn{3}{|c|}{ C. 2 - Costs equipment } & $3,160.00$ \\
\hline \multicolumn{3}{|c|}{ II.a - Investment for real estate usability excluding VAT } & $240,090.00$ \\
\hline \multicolumn{3}{|c|}{ VAT (if not recoverable) } & $52,819.80$ \\
\hline \multicolumn{3}{|c|}{ II.b - Investment for real estate usability including VAT } & $292,909.80$ \\
\hline
\end{tabular}

\section{PART III - INVESTMENT FOR COMMUNICATION AND MARKETING}

\begin{tabular}{l|l|r|l}
\hline Advertising communication & 1 & 800,00 & 800.00 \\
\hline Website & 1 & 12,00 & 12.00 \\
\hline Web designer & 1 & 900,00 & 900.00 \\
\hline Flyers & 500 & 0,05 & 25.00 \\
\hline Advertising posters & 200 & 0,90 & 180.00 \\
\hline $\begin{array}{l}\text { III.a - Investment total for communication and marketing excluding } \\
\text { VAT }\end{array}$ & 1.917 .00 \\
\hline VAT (if not recoverable) & 421.74421 .74 \\
\hline $\begin{array}{l}\text { III.b - Investment total for communication and marketing } \\
\text { including VAT }\end{array}$ & $\mathbf{2 , 3 3 8 . 7 4}$ \\
\hline
\end{tabular}




\section{SUMMARY INVESTMENT}

\begin{tabular}{l|r}
\hline I - Investment for the recovery and re-use of buildings & $3,924,496.84$ \\
\hline II - Investment for real estate usability & $292,909.80$ \\
\hline III - Investment for communication and marketing & $2,338.74$ \\
\hline TOTAL INVESTMENT & $\mathbf{4 , 2 1 9 , 7 4 5 . 3 8}$ \\
\hline
\end{tabular}

\section{Appendix B - ESTIMATED MANAGEMENT COSTS}

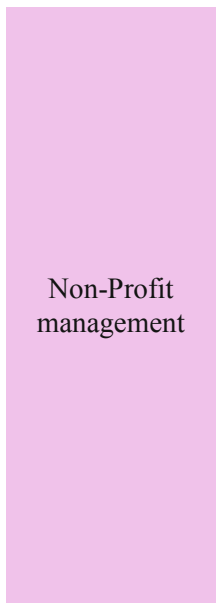

Cost item

Annual cost

\section{Gasometer}

Ordinary maintenance (b)

$€ 8,562.00$

Extraordinary maintenance (c)

$€ 10,702.50$

Staff (human resources)

$€ 18,200.00$

Consumables (a)

$€ 1,060.00$

\section{Valletta Park \\ Ordinary maintenance (b) \\ Extraordinary maintenance (c) \\ Costs for utilities (water)}

$€ 28,750.70$

$€ 35,938.38$

$€ 2,000.00$

Total Valletta Park $€ 66,689.08$

Total Non-Profit management costs $€$ 105,213.58

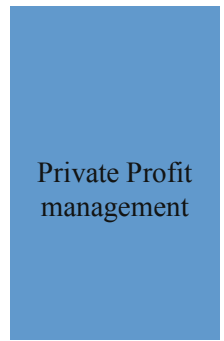

\section{Restaurant area}

Staff (human resources)

$€ 70,800.00$

Raw materials, wines, drinks (Restaurant area) (a)

$€ 53,000.00$

Consumables (a)

$€ 1,590.00$

Industrial laundry (d)

$€ 2,100.00$

Local rental costs; (d) 17 tablecloths for 70 covers ( 1 tablecloth / 4 people) are considered for a cost of euro $0.50 /$ tablecloth. 


\section{Appendix C - ESTIMATED MANAGEMENT REVENUES}

\begin{tabular}{|c|c|c|c|c|}
\hline & & Quantità & Prezzo unitario & Ricavo annuo \\
\hline \multirow{6}{*}{$\begin{array}{l}\text { Non-Profit } \\
\text { management }\end{array}$} & Gasometer & & & \\
\hline & Entrance to the exhibition area & 4,900 visitors/year & $€ 2.00$ & $€ 9,800.00$ \\
\hline & Registration fee for training courses & $50 \mathrm{members} /$ year & $€ 70.00$ & $€ 3,500.00$ \\
\hline & Sale of white mulberries (b) & $8,900 \mathrm{~kg} /$ year $(10 \mathrm{~kg} /$ tree $)$ & $€ 5.00$ & $€ 44,500.00$ \\
\hline & Market place rental (a) & 5 stalls ( 5 days/week) & $€ 800.00$ & $€ 48,000.00$ \\
\hline & Total Gasometer revenues & & & $€ 105,800.00$ \\
\hline \multirow{4}{*}{$\begin{array}{l}\text { Municipality } \\
\text { of Catanzaro }\end{array}$} & Valletta Park & & & \\
\hline & Rent event area & 30 events/year & $€ 500.00$ & $€ 15,000.00$ \\
\hline & Rent restaurant area & 1 local & $€ 2,000.00$ & $€ 24,000.00$ \\
\hline & Total Valletta Park revenues & & & $€ 39,000.00$ \\
\hline \multirow{2}{*}{$\begin{array}{l}\text { Private Profit } \\
\text { management }\end{array}$} & Restaurant area & & & \\
\hline & Revenue restaurant & 13,10456 meals a day / 234 days a year & $€ 15.00$ & $€ 196,560.00$ \\
\hline
\end{tabular}

\section{Appendix D - FEASIBILITY AND ECONOMIC SUSTAIN- ABILITY IN THE MANAGEMENT PHASE TO REGIME}

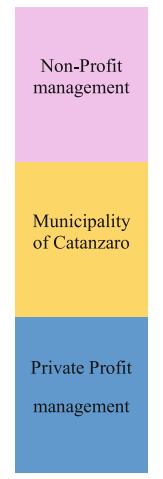

\begin{tabular}{|c|c|c|}
\hline \multicolumn{3}{|l|}{ Gasometer } \\
\hline Revenues & & $105,800.00 €$ \\
\hline \multirow[t]{2}{*}{ Costs } & & $105,213.58 €$ \\
\hline & Net balance & $586.43 \epsilon$ \\
\hline \multicolumn{3}{|l|}{ Valletta Park } \\
\hline Income from rent & & $39,000.00 €$ \\
\hline \multirow[t]{2}{*}{ Costs } & & $0.00 €$ \\
\hline & Net balance & $39,000.00 €$ \\
\hline \multicolumn{3}{|l|}{ Restaurant area } \\
\hline Revenues & & $196,560.00 €$ \\
\hline \multirow[t]{2}{*}{ Costs } & & $151,490.00 €$ \\
\hline & Net balance & $45,070.00 €$ \\
\hline
\end{tabular}




\section{References}

Bourne, L.: Project relationships and the stakeholder circle. In: PMI Research Conference, Centre Mont-Royal, Montreal, Canada (2005)

Calabrò, F., Mallamace, S., Meduri, T., Tramontana, C.: Unused real estate and enhancement of historic centers: legislative instruments and procedural ideas. In: Calabrò, F., Della Spina, L., Bevilacqua, C. (eds.) New Metropolitan Perspectives, ISHT 2018. Smart Innovation, Systems and Technologies - SIST, vol. 101, pp. 464-474. Springer, Cham (2019). https://doi.org/10. 1007/978-3-319-92102-0_49. ISBN: 978-3-319-92098-6, ISSN: 2190-3018

Calabrò, F., Della Spina, L.: The public-private partnership for the enhancement of unused public buildings: an experimental model of economic feasibility project. Sustainability 11, 5662 (2019). https://doi.org/10.3390/su11205662

Calabrò, F., Della Spina, L.: Il Partenariato Pubblico Privato per la valorizzazione degli immobili pubblici inutilizzati. Un modello sperimentale di Progetto di Fattibilità Economica. LaborEst 2018, 16 IS, 1-40 (2018). https://doi.org/10.19254/laborest.16.IS

Della Spina, L.: Adaptive sustainable reuse for cultural heritage: a multiple criteria decision aiding approach supporting urban development processes. Sustainability 12, 1363 (2020). https://doi.org/10.3390/su12041363

Della Spina, L.: Multidimensional assessment for "Culture-Led" and "Community-Driven" urban regeneration as driver for trigger economic vitality in urban historic centers. Sustainability 11, 7237 (2019a). https://doi.org/10.3390/su11247237

Della Spina, L., Calabrò, F.: Decision support model for conservation, reuse and valorization of the historic cultural heritage. In: Gervasi, O., et al. (eds.) Computational Science and Its Applications - ICCSA 2018. ICCSA 2018. Lecture Notes in Computer Science, vol. 10962. LNCS, pp. 3-17. Springer, Cham (2018). https://doi.org/10.1007/978-3-319-95168-3_1

Della Spina, L., Giorno, C., Galati Casmiro, R.: Bottom-up processes for culture-led urban regeneration scenarios. In: Misra, S., et al. (eds.) Computational Science and Its Applications - ICCSA 2019. Lecture Notes in Computer Science, vol. 11622, pp. 93-107. Springer, Cham (2019). https://doi.org/10.1007/978-3-030-24305-0_8

Della Spina, L.: Evaluation decision support models: highest and best use choice. Procedia Soc. Behav. Sci. (2016). https://doi.org/10.1016/j.sbspro.2016.05.323. ISSN: 1877-0428

Della Spina, L., Calabrò, F.: Processo edilizio e stima dei costi. Laborest 11, 1-22 (2015). ISSN: 2421-3187

Della Spina, L.: Historical cultural heritage: decision making process and reuse scenarios for the enhancement of historic buildings. In: Calabrò, F., Della Spina, L., Bevilacqua, C. (eds.) New Metropolitan Perspectives. ISHT 2018. Smart Innovation, Systems and Technologies, vol. 101. Springer, Cham (2018). https://doi.org/10.1007/978-3-319-92102-0_47

Della Spina, L.: A multi-level integrated approach to designing complex urban scenarios in support of strategic planning and urban regeneration. In: Calabrò, F., Della Spina, L., Bevilacqua, C. (eds.) New Metropolitan Perspectives. ISHT 2018. Smart Innovation, Systems and Technologies, vol. 100. Springer, Cham (2019b). https://doi.org/10.1007/978-3-31992099-3_27

Dente, B.: Policy Decisions, 134 p. Springer, Heildelberg (2014). https://doi.org/10.1007/978-3319-02520-9

Dyson, K., Matthews, J., Love, P.E.: Critical success factors of adapting heritage buildings: an exploratory study. Built Environ. Proj. Asset Manag. 6, 44-57 (2015)

Dolores, L., Macchiaroli, M., De Mare, G.: A dynamic model for the financial sustainability of the restoration sponsorship. Sustainability 12(4), 1694 (2020)

Forte, F., De Rossi, B.: Principi di economia ed estimo; Etas: Milano, Italy (1992) 
Fusco Girard, L., Nijkamp, P.: Le valutazioni per lo sviluppo sostenibile della città e del territorio, FrancoAngeli, Milano (1997)

Fusco Girard, L., Gravagnuolo, A.: Circular economy and cultural heritage/landscape regeneration. Circular business, financing and governance models for a competitive Europe. BDC Bollettino Del Centro Calza Bini 17, 35-52 (2017)

Gamboa, G., Munda, G.: The problem of windfarm location: a social multi-criteria evaluation framework. Energy Policy 35, 1564-1583 (2007)

Geissdoerfer, M., Savaget, P., Bocken, N.M.P., Hultink, E.J.: The circular economy-a new sustainability paradigm? J. Clean. Prod. 143, 757-768 (2017)

Ishizaka, A., Nemery, P.: Multi-Criteria Decision Analysis: Methods and Software. Wiley, Chichester (2013)

Kirchherr, J., Reike, D., Hekkert, M.: Conceptualizing the circular economy: an analysis of 114 definitions. Resour. Conserv. Recycl. 127, 221-232 (2017)

Mao, J., Li, C., Pei, Y., Xu, L.: Implementation of a circular economy. In: Circular Economy and Sustainable Development Enterprises, pp. 151-170. Springer, Singapore (2018)

Munda, G.: Social multi-criteria evaluation (SMCE): methodological foundations and operational consequences. Eur. J. Oper. Res. 158, 662-677 (2004)

Nesticò, A., Morano, P., Sica, F.: A model to support the public administration decisions for the investments selection on historic buildings. J. Cult. Heritage 33, 201-207 (2018)

Nesticò, A., Maselli, G.: Sustainability indicators for the economic evaluation of tourism investments on islands. J. Cleaner Prod. 248 (2020). Art. no. 119217. https://doi.org/10.1016/ j.jclepro.2019.119217

Pinto, M.R., De Medici, S., Senia, C., Fabbricatti, K., De Toro, P.: Building reuse: multi-criteria assessment for compatible design. Int. J. Des. Sci. Technol. IJDST 22, 165-193 (2017)

Potting, J., Hekkert, M., Worrell, E., Hanemaaijer, A.: Circular Economy: Measuring Innovation in the Product Chain; Policy Report; PBL Netherlands Environmental Assessment Agency: The Hague, The Netherlands (2017)

Prizzon, F.: Gli Investimenti Immobiliari. Analisi Di Mercato E Valutazione EconomicoFinanziaria degli Interventi. Celid, Torino (1995)

Realfonzo, A.: Teoria e metodo dell'Estimo urbano. Roma, Italy, Nis (1994)

Roscelli, R. (eds.): Manuale di estimo: valutazioni economiche ed esercizio della professione. UTET università (2014)

Saaty, T.L.: Decision Making with Dependence and Feedback: The Analytic Network Process. RWS Publications, Pittsburgh (1996)

Saaty, T.L.: Theory and Applications of the Analytic Network Process. RWS Publications, Pittsburgh (2005)

Saaty, T.L.: The analytic network process. In: Decision Making with the Analytic Network Process; International Series in Operations Research and Management Science, vol. 95, pp. 126. Springer, Boston (2006)

Simon, H.: Theories of bounded rationality. In: McGuire, C.B., Radner, R. (eds.) Decision and Organization, pp. 161-176. North-Holland, Amsterdam (1972)

Vickery, J.: The Emergence of Culture-Led Regeneration: A Policy Concept and Its Discontents; Centre for Cultural Policy Studies: Warwick, UK (2007). http://wrap.warwick.ac.uk/36991/1/ WRAP_Vickery_ccps.paper9.pdf. Accessed 29 Oct 2019

Yang, R.J.: An investigation of stakeholder analysis in urban development projects: empirical or rationalistic perspectives. Int. J. Proj. Manag. 32(5), 838-849 (2014) 
Open Access This chapter is licensed under the terms of the Creative Commons Attribution 4.0 International License (http://creativecommons.org/licenses/by/4.0/), which permits use, sharing, adaptation, distribution and reproduction in any medium or format, as long as you give appropriate credit to the original author(s) and the source, provide a link to the Creative Commons license and indicate if changes were made.

The images or other third party material in this chapter are included in the chapter's Creative Commons license, unless indicated otherwise in a credit line to the material. If material is not included in the chapter's Creative Commons license and your intended use is not permitted by statutory regulation or exceeds the permitted use, you will need to obtain permission directly from the copyright holder. 